\title{
Analysis of the spatial distribution of the indoor radon concentration in school's buildings in Plovdiv province, Bulgaria
}

\author{
K. Ivanova ${ }^{a, *}$, Z. Stojanovska ${ }^{b}$, D. Djunakova ${ }^{\text {a, }}$ J. Djounova ${ }^{\text {a }}$ \\ ${ }^{a}$ National Centre of Radiobiology and Radiation Protection, 3 Sv. Georgi Sofiyski st., 1606, Sofia, Bulgaria \\ ${ }^{\mathrm{b}}$ Faculty of Medical Sciences, Goce Delcev University of Stip, 10-A Krste Misirkov st., 2000, Stip, Macedonia
}

\section{A R T I C L E I N F O}

\section{Keywords:}

Indoor radon

Spatial variation

Schools

Plovdiv-Bulgaria

\begin{abstract}
A B S T R A C T
This paper presents an evaluation of the indoor radon spatial variation between and within school buildings. Radon measurements were carried out in 331 rooms of 16 school buildings in 5 municipalities of Plovdiv province, Bulgaria. They were performed with CR-39 nuclear track detectors exposed over an 8-month period from September 2018 to April 2019. The arithmetic and geometric means together with corresponding standard deviation and geometric standard deviations of the indoor radon concentration were $160 \pm 175 \mathrm{~Bq} / \mathrm{m}^{3}$ and 108 $* / 2.35 \mathrm{~Bq} / \mathrm{m}^{3}$, respectively. The best data fit was achieved with a Weibull 3-parameter function (KolmogorovSmirnov test, $p=0.2916$ ). The effect of the school location and various building characteristics on the indoor radon concentration distribution within a province was investigated. The analyses showed that the factor "year of building construction", which is in general related with the technical condition of the building, imposed the highest impact on the indoor radon concentration difference between schools. The vertical and horizontal components of the indoor radon spatial variability within a school were analysed as well. The results concerning the radon variation within schools could be used to optimize future radon school surveys. In this paper, quality control for indoor radon measurement procedures and radon health impact assessments was included.
\end{abstract}

\section{Introduction}

Approximately $80 \%$ of public exposure is attributable to natural sources of radiation. Among all of them, the most dominant source is the radon accumulated in the indoor environment. Radon $\left({ }^{222} \mathrm{Rn}\right)$ is a radioactive gas, a direct decay product of ${ }^{226} \mathrm{Ra}$ in the ${ }^{238} \mathrm{U}$ chain, which is present in all terrestrial materials. Based on a number of studies, it has been concluded that radon and its decay products account for $40 \%-50 \%$ of the total human exposure over a lifetime [1].

Considering modern life, people spend most of the day indoors, and during indoor activities, they are exposed to radon. Hence, people are exposed to a certain radon level while at home, at work, at school and in other buildings with public access, such as town halls, post offices, hospitals, housing facilities for elderly individuals, shops, and entertainment buildings. The radon dose received by a certain individual primarily depends on the indoor radon concentration and period of exposure. Based on the period of stay, adults obtain the largest contribution to their annual cumulative radon exposure level while they are at home and at work. In contrast, children are mainly exposed to radon at home and at school or kindergarten.
Recent studies have shown that children are more susceptible to radiation exposure than are adults, including natural radiation [2]. Therefore, over the last decade, considerable attention has been paid to radon surveys in schools and kindergartens. In the scientific literature, a number of studies has been published as a result of radon surveys conducted in schools and kindergartens in different countries.

In general, the measured and mean indoor radon concentrations in the literature exhibit a wide range of values, regardless of the size of the study area and the number of measurements. For example, in Slovenia, 730 kindergartens and play schools were surveyed, and the arithmetic mean was $133 \mathrm{~Bq} / \mathrm{m}^{3}$, while the geometric mean reached $58 \mathrm{~Bq} / \mathrm{m}^{3}$ [3]. In Italy, radon surveys were carried out in 2173 schools and kindergartens in six regions, and the radon values ranged from 6 to 1450 $\mathrm{Bq} / \mathrm{m}^{3}$ [4]. In an Irish national radon survey performed in schools, 329 (9\%) buildings were identified to contain one or more rooms with radon concentrations above $400 \mathrm{~Bq} / \mathrm{m}^{3}$ (reference level), and a remediation programme was implemented [5].

The studies concerning the indoor radon spatial distribution have focused on the spatial characteristics within regions (or specific regions) or/and on the variability within buildings. Some of these studies are

\footnotetext{
* Corresponding author.

E-mail address: k.ivanova@ncrrp.org (K. Ivanova).
} 
described in the following.

Bochicchio et al. [6] improved the estimation of this variability with a study that involved 334 primary school buildings in Serbia, mostly with one or two levels. The analysis considered radon concentrations measured in 693 rooms. They reported a higher variability between schools $(\mathrm{CV}=65 \%)$ than that between floors $(\mathrm{CV}=24 \%)$ and between rooms on the same floor $(\mathrm{CV}=21 \%)$.

In Porto city (Portugal), Madureira et al. [7] studied the indoor spatial variation in 13 public primary schools monitored over 2 months (in the heating season) with radon measurements. In regard to the 4 schools with at least two floors, a floor-to-floor variation was found, with a median value of $14.5 \%$. Furthermore, they reported median room-to-room variations of $30.9 \%$ on the ground floor and of $14.5 \%$ on the upper floor, which are lower than the variations between all schools $(\mathrm{CV}=73.1 \%)$. Similar median room-to-room variations on the ground $(\mathrm{CV}=27 \%)$ and first floor $(\mathrm{CV}=14 \%)$ were obtained in a survey performed in 50 schools in the Republic of Srpska [8].

The first indoor radon concentration survey in Bulgaria started with radon measurements in dwellings in several cities in 2012 [9]. Bulgaria adopted the Basic Safety Standards (BSS) directive, which contains a recommendation for the reduction in the annual average radon concentration not only in dwellings but also in buildings with public access and workplaces. Therefore, in the same year, indoor radon measurements were performed in 256 kindergartens in Sofia city over a period of 3 months, starting in February and lasting up to April 2013 [10]. Research continued with a new campaign during the cold period of 2014, including radon measurements in 174 kindergartens in three cities where the radon concentration again greatly varied [11]. Based on the experience gained in these surveys, a national survey was performed in dwellings (2015-2016) [12,13].

Furthermore, the schools represent a particular type of building with public access in regard to the problem of indoor radon monitoring. Considering school building construction as well occupation conditions, size and number of rooms, ventilation options, etc., it is simply impossible to apply the same radon measurement and control approaches in dwellings and buildings with public access.

To verify the national measurement protocol for indoor radon surveys in buildings with public access, a project funded by Bulgarian National Science was started in 2018. A certain segment of the project included the evaluation of the indoor radon spatial variation among and within school buildings with different characteristics. These results are presented and examined in this paper.

\section{Material and methods}

\subsection{Design of the survey}

The survey was organized by the National Centre of Radiobiology and Radiation Protection of Bulgaria with support provided by Regional Health Inspectorates in terms of the distribution of detectors. The survey considered radon measurements in several schools in Plovdiv province, located in the central part of southern Bulgaria. It comprises $18 \mathrm{mu}-$ nicipalities characterised by a diverse relief, parts of which belong to the Upper Thracian Plain, the Rhodopes, Sredna Gora, the Sub-Balkan valleys and Stara Planina, and it contains an abundance of mineral springs. The Plovdiv region is one of the most seismically active regions in Bulgaria [14]. According to previous radon surveys performed in dwellings [9] and kindergartens [11], high radon concentrations are also expected in schools in Plovdiv province.

In this survey, the radon concentration was measured in 16 buildings of 14 primary schools in 5 municipalities. To generate a representative sample, municipalities were selected to cover the whole territory, considering the different geographical units in the province and number of populations. Accordingly, two municipalities (Karlovo and Sopot) are located in the northern part of Plovdiv Province in a plain, and two others (Asenovgard and Parvomaj) are situated in the southern part, which is a mountainous area, while the Plovdiv municipality is located in the central part of the region (Fig. 1). The schools were selected randomly within these municipalities. The number of pupils and workers in each school are listed in Table 1 Two of the investigated schools are situated into two building. Buildings with ID numbers 7 and 8 belong to one school and buildings with ID 10 and 11 too.

Following the requirements given in the national procedure, in each school, radon measurements were performed in all permanently occupied rooms. Permanently occupied rooms are rooms that are typically used longer than $1 \mathrm{~h}$ each day. A classroom, a playroom, an office, a canteen/dining room, a music room, a work room or a gym hall are all examples of permanently occupied rooms. Restrooms, technical rooms, storerooms, etc. Are rooms that are not permanently occupied. Overall, 408 detectors were deployed in 352 classrooms, 27 gymnasiums, 8 dining rooms (canteens) and 21 offices. For quality control purposes, an additional 20 detectors were installed for duplicate measurements. At the end of the exposure period, some of the detectors were missing. The loss of $19 \%$ in this survey was higher than the detector losses in our previous surveys in residential buildings, which was expected. Higher losses were expected because the surveyed buildings and rooms are used by young pupils. Finally, the total number of analysed detectors was 347 , of which 16 were duplicate detectors. The numbers of deployed and analysed detectors per school in addition to the detector losses in $\%$ are summarized in Table 1.

In the rooms, radon CR-39 detectors were positioned at a distance of 1-1.5 m above the floor or any wall surface to measure radon concentration in the air, which is the most representative of breathing air. Additionally, the measuring locations were chosen far from heating sources and windows [15]. To satisfy the above requirements, most of the CR-39 detectors were suspended from ceilings.

The survey started at the beginning of the school year with detector deployment in September 2018 and finished with detector collection in April 2019. We assumed that the results of the indoor radon concentration obtained through detector exposure over a period of approximately 8 months (covering the autumn, winter and part of the spring season) represented the annual radon concentrations [16,17].

Questionnaires to collect information about the type of building construction and other information were completed. Select obtained information is summarized in Table 2.

\subsection{Indoor radon measurement and data analysis}

The indoor radon concentration $\left(C_{\mathrm{Rn}}\right)$ measurements in the school rooms were performed with RSKS-type nuclear track detectors produced by Radosys, which consisted of a CR-39 radon-sensitive chip enclosed in a diffusion chamber. The detection range of applied detectors is from 40 to $8000 \mathrm{kBqh} / \mathrm{m}^{3}$, according to the manufacturer. After expiration of the exposure period, the detectors were collected, each of which was placed in two plastic bags and sent to the laboratory of the National Centre of Radiobiology and Radiation Protection for processing. Each detector and CR-39 chip contained an ID code from the manufacturer to avoid mix-ups. Following the ISO 11665-4 (2012) methodology, the process considered a few steps. First, the detectors were mechanically opened to remove the chips from the chambers, and they were further chemically etched for $3 \mathrm{~h}$ and $40 \mathrm{~min}$ in a $6.25 \mathrm{M} \mathrm{NaOH}$ solution at $90-93^{\circ} \mathrm{C}$ [18]. In the next step, the formed tracts were counted using an automated image analysis system with an optical microscope. The radon concentration was evaluated based on the counted track density by applying a calibration factor as well as background corrections. Due to quality assurance procedures, the calibration factor was estimated through detectors exposed to radon reference atmospheres of 200, 500, 1000 and 2000 $\mathrm{Bq} / \mathrm{m}^{3}$ in the Radon Calibration Service Laboratory of the Federal Office for Radiation Protection (BfS), Germany.

The measured $C_{\mathrm{Rn}}$ together with the information retrieved from filled questionnaires were further analysed. For that purpose, XLSTAT Pro 7.5 (version 2014.5.03) statistical software was employed. To determine the 


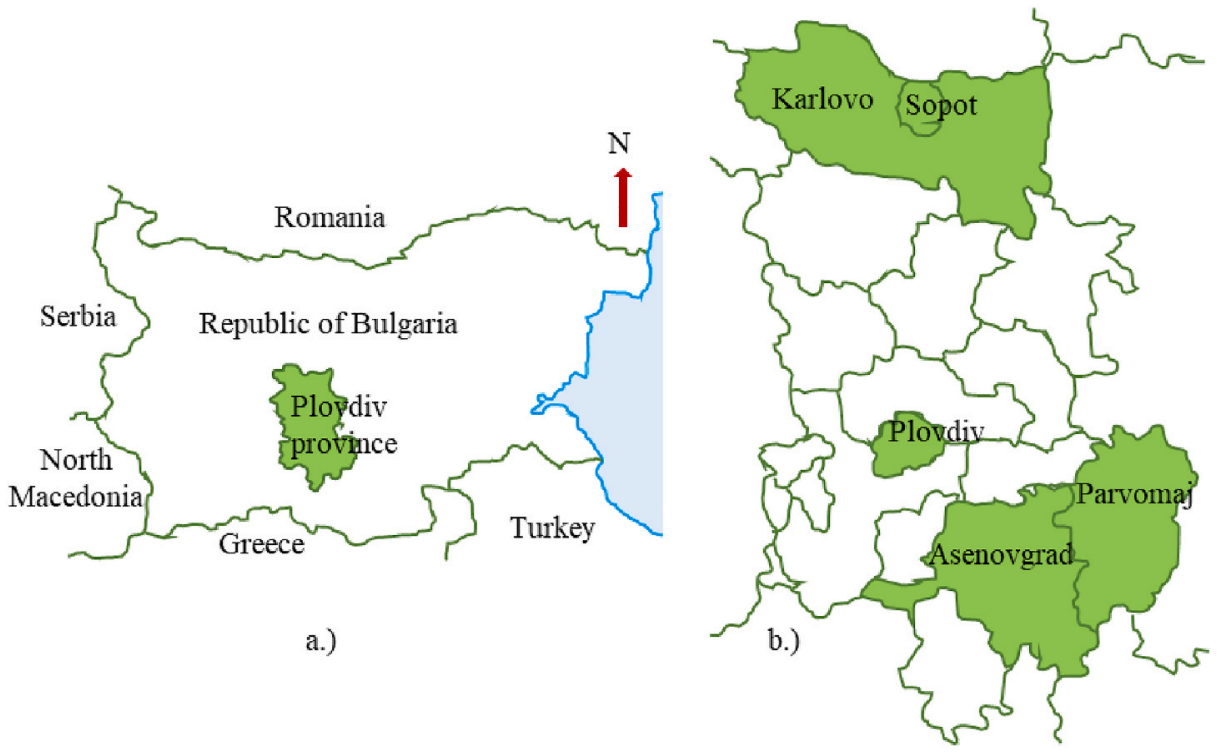

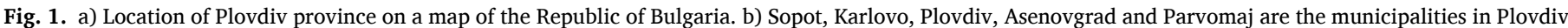
province where the radon surveys in schools are performed.

Table 1

Numbers of pupils, workers, deployed detectors and relative detector losses in each school in the 5 municipalities.

\begin{tabular}{lllllll}
\hline ID & Municipality & $N_{\mathrm{s}}$ & $N_{\mathrm{w}}$ & $N_{\mathrm{d}}$ & $N_{\mathrm{a}}$ & $D_{1}$ \\
\hline 1 & Plovdiv & 472 & 50 & 24 & 21 & $13 \%$ \\
5 & Plovdiv & 431 & 53 & 36 & 30 & $17 \%$ \\
6 & Plovdiv & 259 & 36 & 16 & 15 & $6 \%$ \\
7 & Plovdiv & 389 & 47 & 17 & 16 & $6 \%$ \\
8 & Plovdiv & & & 12 & 10 & $17 \%$ \\
9 & Plovdiv & 172 & 35 & 26 & 25 & $4 \%$ \\
12 & Plovdiv & 1292 & 115 & 49 & 45 & $8 \%$ \\
13 & Plovdiv & 870 & 70 & 38 & 31 & $18 \%$ \\
14 & Plovdiv & 353 & 40 & 25 & 20 & $20 \%$ \\
15 & Plovdiv & 397 & 38 & 17 & 16 & $6 \%$ \\
16 & Asenovgrad & 666 & 62 & 49 & 23 & $53 \%$ \\
10 & Asenovgrad & 495 & 50 & 15 & 10 & $33 \%$ \\
11 & Asenovgrad & & & 16 & 7 & $56 \%$ \\
2 & Parvomaj & 75 & 13 & 14 & 14 & $0 \%$ \\
3 & Kalovo & 418 & 34 & 28 & 28 & $0 \%$ \\
4 & Sopot & 286 & 41 & 26 & 20 & $23 \%$ \\
& Total & 6575 & 684 & 408 & 331 & $19 \%$ \\
\hline
\end{tabular}

Legend: ID-School's building, $N_{\mathrm{s}}$-number of pupils, $N_{\mathrm{s}}$-number of workers, $N_{\mathrm{d}^{-}}$ number of deployed detectors, $N_{\mathrm{a}}$-number of analysed detectors, $D_{\mathrm{l}}$-relative loss. relation between $C_{\mathrm{Rn}}$ variations and certain building characteristics (named factors), univariable analysis was performed. In the analysis, depending on the distribution and homogeneity of the grouped $C_{\mathrm{Rn}}$ results, appropriate parametric and nonparametric statistical tests were applied at the $95 \%$ confidence level. The null hypothesis concerned the occurrence of a significant difference between the $C_{\mathrm{Rn}}$ data categorized by the tested factors, and the relation between the above factors and $C_{\mathrm{Rn}}$ was quantified using the squared correlation ratio $(\eta)$. The squared correlation ratio $(\eta)$ is defined as the ratio between two standard deviations, namely, that within the individual categories and that within the $C_{\mathrm{Rn}}$ data. $\eta$ is generally between 0 and 1 , and the closer $\eta$ is to 1 , the stronger the relationship between the factor and $C_{\mathrm{Rn}}$ is. For each factor, $\eta$ was tested to determine whether the value was significantly different from 0 .

\section{Results and discussion}

\subsection{Quality control of the $C_{R n}$ measurements}

To verify the accuracy of the evaluation process, duplicate measurements of $C_{\mathrm{Rn}}$ were performed. In a randomly selected room in each school, paired detectors were deployed, and they remained in the rooms

Table 2

Select characteristics of the school buildings/rooms where the indoor radon concentration was measured.

\begin{tabular}{|c|c|c|c|c|c|c|c|c|}
\hline ID & Year of construction & Building materials & Rooms & Floors & Basement & Heating & Ventilation & Efficiency measure \\
\hline 1 & 1962 & brick & c, o & $F, G$ & no & Gas & No & No \\
\hline 5 & 1918 & stone & $\mathrm{c}, \mathrm{o}, \mathrm{d}, \mathrm{g}$ & $\mathrm{F}, \mathrm{G}$ & yes & Central & No & Yes \\
\hline 6 & 1934 & reinforced concrete & $\mathrm{c}, \mathrm{o}, \mathrm{d}, \mathrm{g}$ & $\mathrm{F}, \mathrm{G}$ & yes & Local & Yes & Yes \\
\hline 7 & 1940 & brick & $c, o$ & $\mathrm{~F}, \mathrm{G}$ & no & Gas & Yes & Yes \\
\hline 8 & 1940 & brick + wood & $\mathrm{c}, \mathrm{o}, \mathrm{g}$ & $\mathrm{F}, \mathrm{G}$ & no & Gas & Yes & Yes \\
\hline 9 & 1928 & brick & $\mathrm{c}, \mathrm{o}, \mathrm{d}, \mathrm{g}$ & $\mathrm{F}, \mathrm{G}$ & yes & Local & Yes & Yes \\
\hline 12 & 1978 & brick & $\mathrm{c}, \mathrm{o}, \mathrm{d}, \mathrm{g}$ & $\mathrm{F}, \mathrm{G}$ & yes & Electricity & No & Yes \\
\hline 13 & 1968 & reinforced concrete & $\mathrm{c}, \mathrm{o}, \mathrm{g}$ & $\mathrm{F}, \mathrm{G}$ & yes & Central & No & Yes \\
\hline 14 & 1934 & reinforced concrete & $c, o, d$ & $F, G$ & yes & Electricity & No & Yes \\
\hline 15 & 1924 & reinforced concrete & $\mathrm{c}, \mathrm{o}, \mathrm{d}, \mathrm{g}$ & $\mathrm{F}, \mathrm{G}$ & yes & Electricity & No & No \\
\hline 16 & 1945 & brick & $\mathrm{c}, \mathrm{o}, \mathrm{g}$ & $F, G, S$ & yes & Gas & No & Yes \\
\hline 10 & 1947 & brick & $c, o$ & $F, G, S$ & yes & Gas & No & No \\
\hline 11 & 1947 & brick & c & $\mathrm{F}, \mathrm{G}$ & no & Gas & No & Yes \\
\hline 2 & 1929 & reinforced concrete & $c, o, d, g$ & G & no & Central & No & Yes \\
\hline 3 & 1948 & reinforced concrete & $\mathrm{c}, \mathrm{o}, \mathrm{d}, \mathrm{g}$ & $F, G, S$ & no & Central & No & Yes \\
\hline 4 & 1938 & brick & $\mathrm{c}, \mathrm{o}, \mathrm{d}$ & $\mathrm{F}, \mathrm{G}$ & yes & Central & Yes & Yes \\
\hline
\end{tabular}

Legend: ID-School's building, c-classroom, o-office, d-dining room, g-gym, F-first floor, G-ground floor, S-second floor. 
throughout the exposure period. The results of the duplicate $C_{\mathrm{Rn}}$ measurements in the 16 schools are plotted in Fig. 2.

The null hypothesis whereby the difference between $C_{\mathrm{Rn} 1}$ (the radon concentration of the first detector) and $C_{\mathrm{Rn} 2}$ (the radon concentration of the second detector) is equal to 0 was accepted at the $95 \%$ confidence level, and the $p$-value was greater than 0.05 ( $t$-test, $p=0.9851$ ).

To analyse whether differences occur between the measured concentrations by each pair of detectors, we applied the $U$ test, defined by the following equation:

$$
U=\frac{\left|C_{R n 1}-C_{R n 2}\right|}{\sqrt{\sigma_{C R n 1}^{2}-\sigma_{\sigma_{C R n} 2}^{2}}}
$$

where $C_{\mathrm{Rn} 1}$ and $C_{\mathrm{Rn} 2}$ are the paired radon concentrations and $\sigma_{\mathrm{CRn} 1}$ and $\sigma_{\mathrm{CRn} 2}$, respectively, are the corresponding combined uncertainties, including the uncertainties of calibration, background concentration and exposure period. The uncertainty of the evaluation process has been explained in more detail by Stojanovska et al. [19].

Furthermore, the obtained $U$ values were compared to predefined critical levels, which in fact corresponded to the critical values obtained from $t$-statistic tables at the given confidence level. In our case, the acceptable limiting value of the $U$ test was set to 1.65 at the $95 \%$ probability level. In the case when the $U$ values were $1.65<U<2.00$, the results occurred at the warning level, and at $U>2$, they were not acceptable. In the study, in regard to 14 paired radon concentrations, the value of $U$ was $<1$, which confirmed the acceptable reproducibility of the measured results. In two cases, $U>1.65$, and in the first case, $U=$ 2.1 , and the warning level was $C_{\mathrm{Rn}}>100 \mathrm{~Bq} / \mathrm{m}^{3}$. Moreover, in the second case, at $U=3.0$, unacceptable results were obtained for $C_{\mathrm{Rn}}>100 \mathrm{~Bq} /$ $\mathrm{m}^{3}$. This discrepancy was probably random as a consequence of the sampling process and motivates more detailed research in this direction.

\subsection{Data characterization}

The data in the survey consisted of the $C_{\mathrm{Rn}}$ results measured in 331 rooms of 16 school buildings in Plovdiv province. A histogram of the $C_{\mathrm{Rn}}$ values is shown in the left panel of Fig. 3. The data are right-skewed, and in $50 \%$ (164 rooms), the $C_{\mathrm{Rn}}$ value was below $100 \mathrm{~Bq} / \mathrm{m}^{3}$, while in $11 \%$ (36 rooms), the $C_{\mathrm{Rn}}$ value was above reference level of $300 \mathrm{~Bq} / \mathrm{m}^{3}$ as set by national legislation The goodness of fit test proves that the best fit of the data is achieved with a Weibull 3-parameter function. The difference between the cumulative distributions of the measured $C_{\mathrm{Rn}}$ values and the theoretically estimated $C_{\mathrm{Rn}}$ values with the Weibull 3-parameter function were insignificant (Kolmogorov-Smirnov test, $p=0.2916$ ), as shown in the right panel of Fig. 3.

Descriptive statistics of $C_{\mathrm{Rn}}$, as measured in the rooms of all school buildings, as well as statistics of the $C_{\mathrm{Rn}}$ values measured in the rooms of the school buildings in each municipality, are listed in Table 3. Generally, the geometric mean values of $C_{\mathrm{Rn}}$ are closer to the corresponding median values than to the arithmetic mean values. This occurs because the $C_{\mathrm{Rn}}$ distribution is not a normal distribution (KS, $p<0.05$ ), so in this survey, the average values are expressed as the geometric mean (GM) values and the corresponding geometric standard deviation (GSD) values.

Based on the measurements of $C_{\mathrm{Rn}}$ in this survey, the GM (with the GSD in parentheses) was found to be $108 \mathrm{~Bq} / \mathrm{m}^{3}$ (2.34). The GM and GSD of $C_{\mathrm{Rn}}$ in the Plovdiv province (the first column in Table 1) are higher than the values of $\mathrm{GM}=81 \mathrm{~Bq} / \mathrm{m}^{3}$ and $\mathrm{GSD}=2.15$, respectively, of $C_{\mathrm{Rn}}$, which represent the national $C_{\mathrm{Rn}}$ value [12]. However, the GM and GSD of $C_{\mathrm{Rn}}$ in this survey are lower than the values of $\mathrm{GM}=197$ $\mathrm{Bq} / \mathrm{m}^{3}$ and $\mathrm{GSD}=2.16$, respectively, reported in a survey in a kindergarten performed in the same region during the winter period covering 3-4 months in 2014 [11]. This difference can be explained by the difference in the duration of the exposure period and by the difference in building construction method of the kindergartens and schools, as well as their usage pattern, which is not considered. In general, school buildings are larger than kindergartens, and schools are occupied longer each day than are kindergartens. It is also considered that the opening of windows during school occupation is not limited, in contrast to kindergartens where windows are opened only during a certain period of the day.

Based on Table 3, it is found that the $C_{\mathrm{Rn}}$ value in the rooms of the school buildings in Plovdiv province ranges from 24 to $995 \mathrm{~Bq} / \mathrm{m}^{3}$. Apart from the wide interval, the values of $C_{\mathrm{Rn}}$ exhibit a pronounced variation. The variations in $C_{\mathrm{Rn}}$ across the whole region, expressed by the variation coefficient ( $\mathrm{CV}=109 \%$ ) and the geometric standard deviation $(\mathrm{GM}=2.34)$, are higher than the variations within the municipalities.

The relation between the $C_{\mathrm{Rn}}$ variation and municipality is statistically significant $(p<0.0001)$, with a squared correlation ratio of $\eta=$ 0.24 (Table 4). We assume that this relation primarily occurs due to differences in the geology, geographical position and building characteristics of the schools, both between the municipalities and within themselves.

Comparing CV and GSD between the municipalities, it is concluded that the corresponding variations in $C_{\mathrm{Rn}}$ also differ. Therefore, the

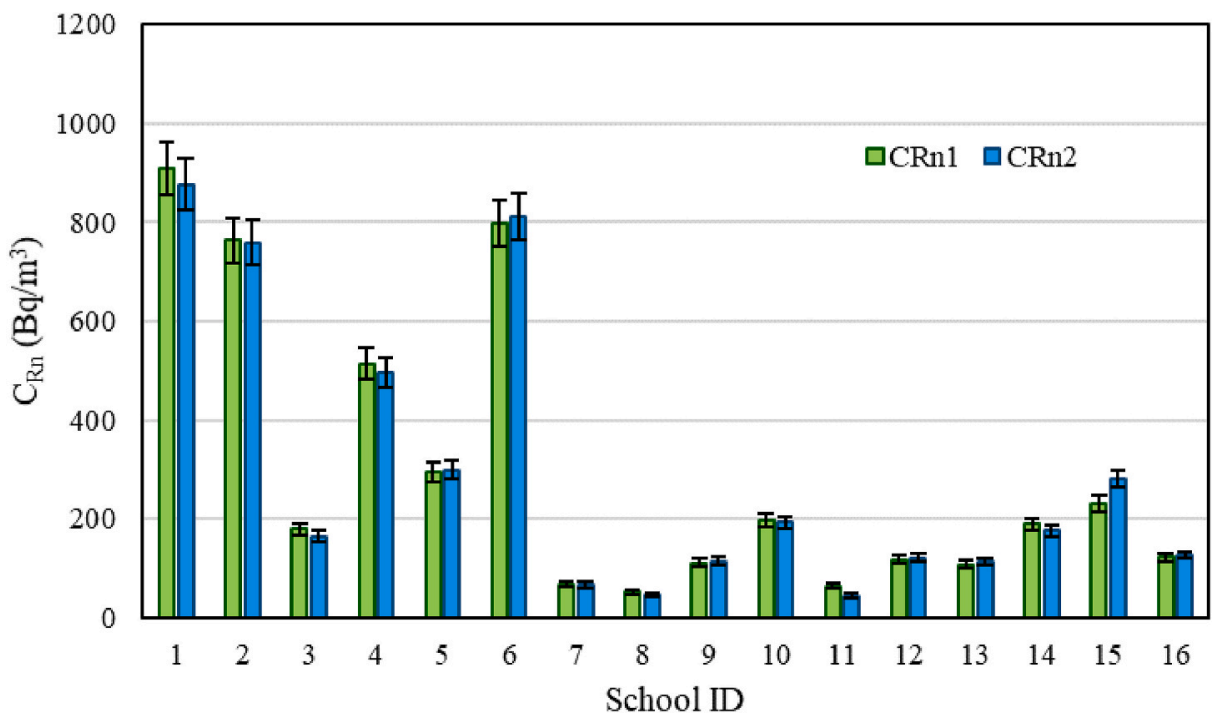

Fig. 2. Reproducibility of the radon results measured with the duplicated detectors. 

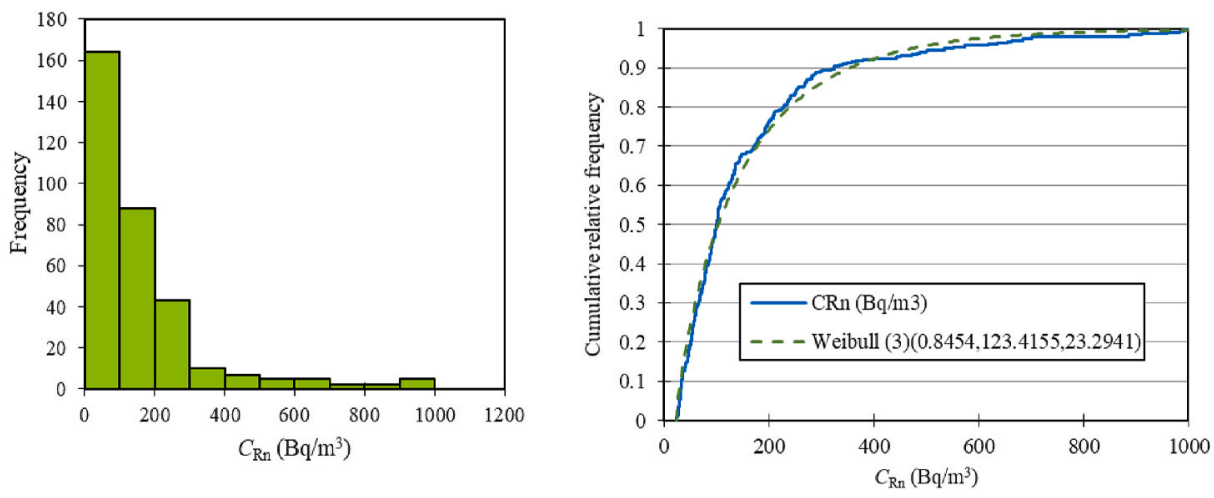

Fig. 3. Left - Histogram of $C_{\mathrm{Rn}}$; right - cumulative distribution of the measured and estimated $C_{\mathrm{Rn}}$ values with the Weibull ( $\beta=0.85$, $\gamma=123.42$, $\left.\mu=23.29\right)$ function.

Table 3

Descriptive statistics of $C_{\mathrm{Rn}}$

\begin{tabular}{|c|c|c|c|c|c|c|}
\hline \multirow[t]{2}{*}{ Statistic } & \multicolumn{6}{|l|}{$C_{\mathrm{Rn}}\left(\mathrm{Bq} / \mathrm{m}^{3}\right)$} \\
\hline & Plovdiv province & Asenovgrad & Karlovo & Plovdiv & Parvomaj & Sopot \\
\hline No. of observations & 331 & 40 & 28 & 229 & 14 & 20 \\
\hline Minimum & 24 & 42 & 27 & 24 & 224 & 102 \\
\hline Maximum & 995 & 278 & 211 & 959 & 984 & 995 \\
\hline Median & 100 & 88 & 58 & 101 & 471 & 253 \\
\hline Arithmetic mean & 160 & 95 & 74 & 148 & 481 & 326 \\
\hline Standard deviation & 175 & 47 & 45 & 155 & 244 & 254 \\
\hline Variation coefficient & $109 \%$ & $49 \%$ & $60 \%$ & $105 \%$ & $49 \%$ & $76 \%$ \\
\hline Geometric mean & 108 & 87 & 64 & 102 & 430 & 268 \\
\hline Geometric standard deviation & 2.34 & 1.49 & 1.69 & 2.33 & 1.64 & 1.82 \\
\hline
\end{tabular}

Table 4

Squared correlation ratio together with p value (on the $95 \%$ confidence level) expressed influence of each considered factor on the $C_{R n}$ variations.

\begin{tabular}{llc}
\hline Factors & Squared correlation ratio & $p$-values \\
\hline Municipality & 0.24 & $<0.0001$ \\
School & 0.36 & $<0.0001$ \\
Year of construction & 0.39 & $<0.0001$ \\
Building materials & 0.02 & $<0.0001$ \\
Rooms & 0.06 & $<0.0001$ \\
Tipe of heating & 0.02 & $<0.0001$ \\
Ventilation system & 0.04 & 0.0249 \\
Energy efficiency measure & 0.009 & 0.2096 \\
Floor & 0.12 & $<0.0001$ \\
Floor in buildings with basement & 0.20 & $<0.0001$ \\
Floor in buildings without basement & 0.10 & $<0.0001$ \\
\hline
\end{tabular}

highest variation in $C_{\mathrm{Rn}}$ occurs in the municipality of Plovdiv ( $\mathrm{CV}=$ $105 \%$ and GSD $=2.33$ ), while the lower are in the neighbouring municipalities Karlovo (CV $=60 \%$ and GSD $=1.69)$ and Sopot $(\mathrm{CV}=76 \%$ and $\mathrm{GSD}=1.82$ ) and the lowest appeared in Asenovgrad (CV $=49 \%$ and $\mathrm{GSD}=1.49)$ and Parvomaj (CV $=49 \%$ and GSD $=1.64)$. The grouping of variations into three groups confirms the influence of the geographical position of the buildings on the radon variations between the municipalities.

Apart from the above variations, the differences in the GM values of $C_{\mathrm{Rn}}$ between the municipalities are also obvious. The $C_{\mathrm{Rn}}$ value in the municipalities of Parvomaj and Sopot is significantly higher than that in the other municipalities (Kruskal-Wallis test, $p<0.0001$ ). Considering that in these two municipalities the concentrations of radon are higher than the municipalities with which they are bordered, the assumption arises that the differences are from the differences in geology.

\section{3. $C_{R n}$ difference between the school buildings}

Further analysis showed that the difference between the school building $C_{\mathrm{Rn}}$ values were significant at a higher level, from Table $4 \eta=$ $0.36(p<0.0001)$, than that of the $C_{\mathrm{Rn}}$ value difference between the municipalities. The GM and GSD of $C_{\mathrm{Rn}}$ in each school buildings are shown in Fig. 4. The figure shows that the highest $\mathrm{GM}=430 \mathrm{~Bq} / \mathrm{m}^{3}$ occurred in building 2 in the Parvomaj municipality, while the lowest $\mathrm{GM}=42 \mathrm{~Bq} / \mathrm{m}^{3}$ occurred in the school buildings of ID 12 in Plovdiv. Despite the $C_{\mathrm{Rn}}$ variations between the school buildings, a variation in $C_{\mathrm{Rn}}$ within each building was also observed. As a result, the GSD values of $C_{\mathrm{Rn}}$ greatly varied, ranging from GSD $=1.20$ for building 11 in Asenovgrad to GSD $=2.66$ for building 14 in the Plovdiv municipality (Fig. 4). The calculated CV for each school ranged from 17\% (building 11 ) to $117 \%$ (building 14 ), with a median value of $64 \%$. The conducted tests demonstrated that there exists no correlation between the variations (GSD and CV values) and the number of $C_{\mathrm{Rn}}$ measurements in the building.

According to the above, it is assumed that the variations between the schools are influenced by the differences in the geology, geographical position and characteristics of the buildings and rooms, while the variations within the schools originate from the differences in the local geology and room characteristics. To clarify this assumption, in the following, analyses of the effect of certain building characteristics on the $C_{\mathrm{Rn}}$ variations are conducted.

First, the relationship between $C_{\mathrm{Rn}}$ and the year of building construction was considered, which was significant with a squared correlation ratio of $\eta=0.39(p<0.0001)$, (Table 4). The GM and corresponding GSD values of the $C_{\mathrm{Rn}}$ data grouped according to the year of building construction are shown in Fig. 5. In general, it is found that the average values of $C_{\mathrm{Rn}}$ in buildings built up to 1938 are higher than those in buildings constructed after 1938. Exceptions to this trend are the GM values of $C_{\mathrm{Rn}}$ in buildings constructed in 1962 and perhaps in one built in 1947. This situation is in line with expectations, with higher $C_{\mathrm{Rn}}$ values in old buildings than in new buildings. This occurs due to the presence of micro- and macro-cracks in the building structure, which are more likely to be present in old buildings than in new buildings through which radon from the underlying soil easily enters into indoor. A similar 


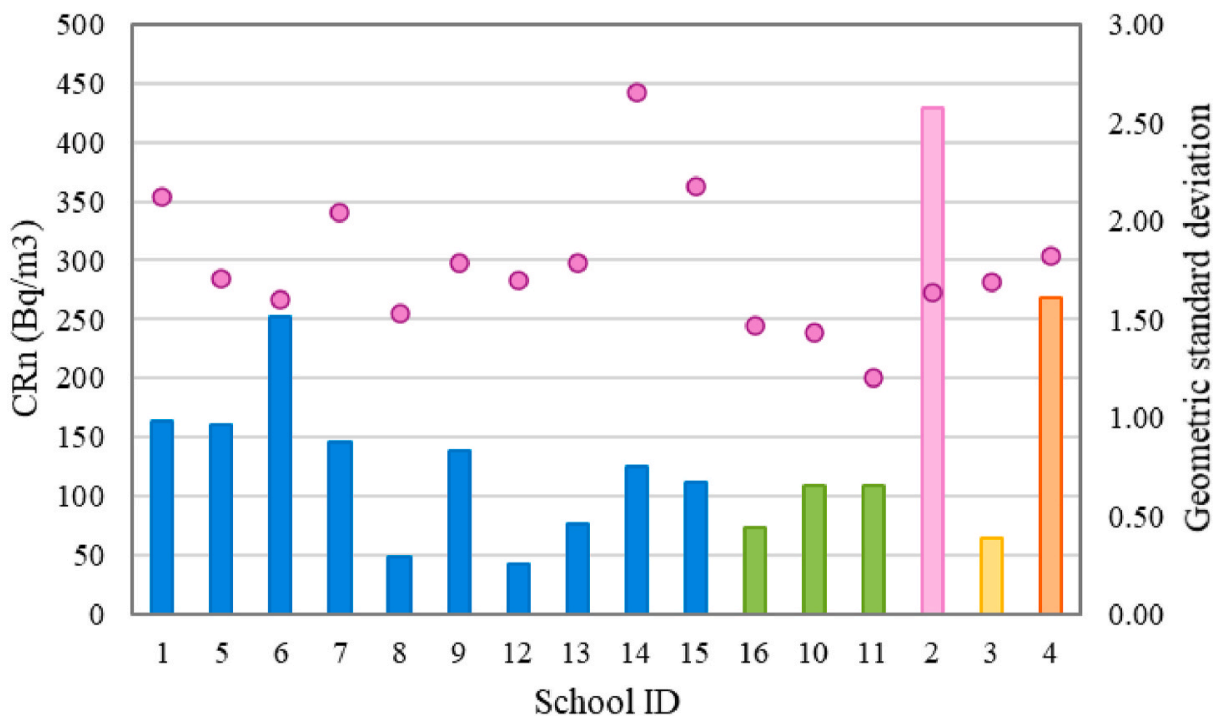

Fig. 4. Bar diagram of the $\mathrm{C}_{\mathrm{Rn}}$ geometric mean values for the schools in the Plovdiv (blue), Asenovgrad (green), Parvomaj (pink), Karlovo (yellow) and Sopot (orange) municipalities together with the geometric standard deviation of $C_{\mathrm{Rn}}$ for each school. (For interpretation of the references to colour in this figure legend, the reader is referred to the Web version of this article.)

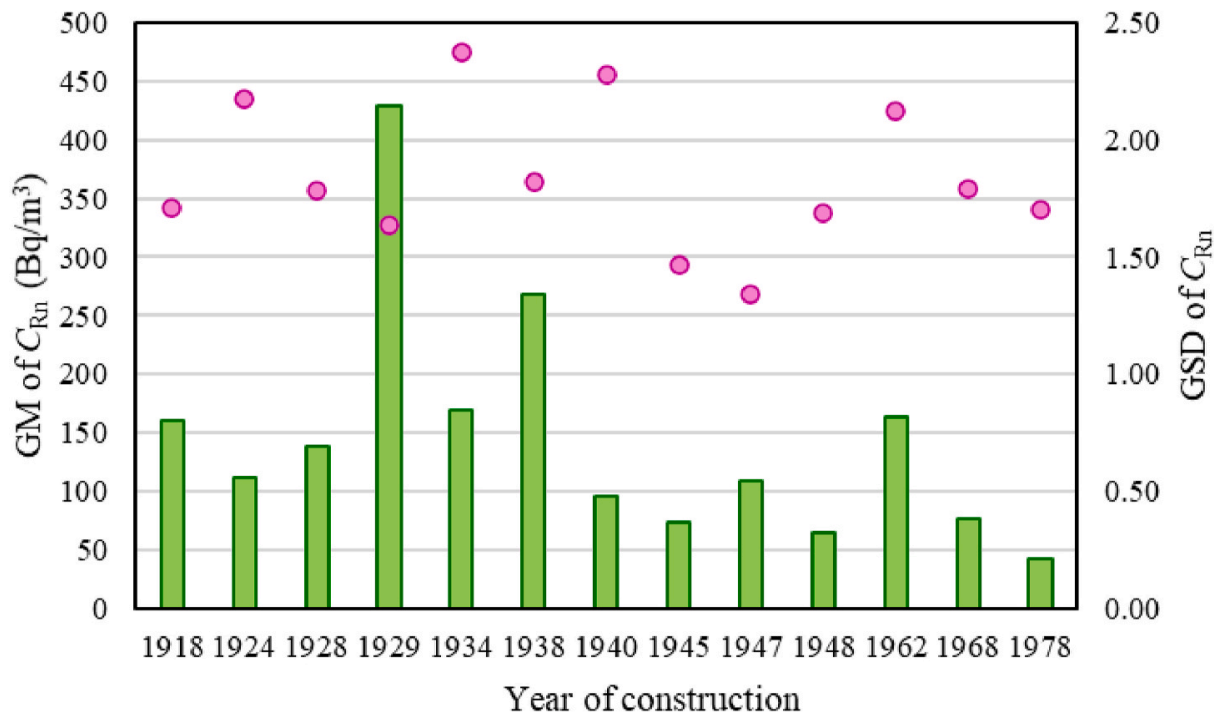

Fig. 5. Bar diagram of the $\mathrm{C}_{\mathrm{Rn}}$ geometric mean (GM) and geometric standard deviation (GSD) values in the schools according to the year of construction.

effect of the influence of year of construction on the $C_{\mathrm{Rn}}$ level was found in a kindergarten survey in 2014 [10].

Based on published papers, it is found that when building materials contain high ${ }^{226} \mathrm{Ra}$ concentrations, they comprise a significant source of $C_{\mathrm{Rn}}$ (among others: [20-23]. As such, the impact of building materials on the obtained $C_{\mathrm{Rn}}$ variations was examined and found to be significant $(p<0.0001)$ but with a low value of the squared correlation ratio $\eta=$ 0.02 (Table 4), The GM and GSD values of the $C_{\mathrm{Rn}}$ data grouped according to the building materials are shown as a bar diagram in Fig. 6. The analysis reveals that the highest $C_{\mathrm{Rn}}$ value is measured in buildings made of stone, while the lowest $C_{\mathrm{Rn}}$ value is measured in buildings made of wood and stone. Between these two extremes are the values of $C_{\mathrm{Rn}}$ measured in buildings constructed of brick and reinforced concrete, which do not differ from each other. For example, a low $C_{\mathrm{Rn}}$ in wooden buildings was also reported by Karpińska et al. [24] and Torgal et al. [25]. Fig. 6 clearly shows that the variations in $C_{\mathrm{Rn}}$ in buildings made of stone and wood are lower than the variations in buildings made of brick and reinforced concrete. The low GSD value of $C_{\mathrm{Rn}}$ in stone buildings may occur due to the use of local stone material for construction that do not differ between the various schools. In contrast, the use of brick and concrete of different origins may be one of the reasons for the high GDS values of $C_{\mathrm{Rn}}$ in these buildings.

Usually, schools contain rooms that are used for different purposes, such as classrooms, gyms, dining rooms (canteens), and offices. Therefore, in this study, the effect of the room type on the radon variation was analysed, and a significant correlation was obtained at $\eta=0.06(p<$ 0.0001 ), (Table 4). The GM and GSD values of the $C_{\mathrm{Rn}}$ data grouped by the room type are plotted in Fig. 7. The analysis showed that the $C_{\mathrm{Rn}}$ value in the classrooms was significantly lower than that measured in the other rooms, while the highest GM value of $C_{\mathrm{Rn}}$ occurred in the dining rooms. The reason for this could be related to its usual location on the basement floor. The clear grouping of the results may also be associated with the mode of use. This indicates that during the day the classrooms are the most occupied rooms over the other rooms, due to which the air circulation is high. It is worth noting that the $C_{\mathrm{Rn}}$ value is connected with the specific use of the rooms, and the results depend on 


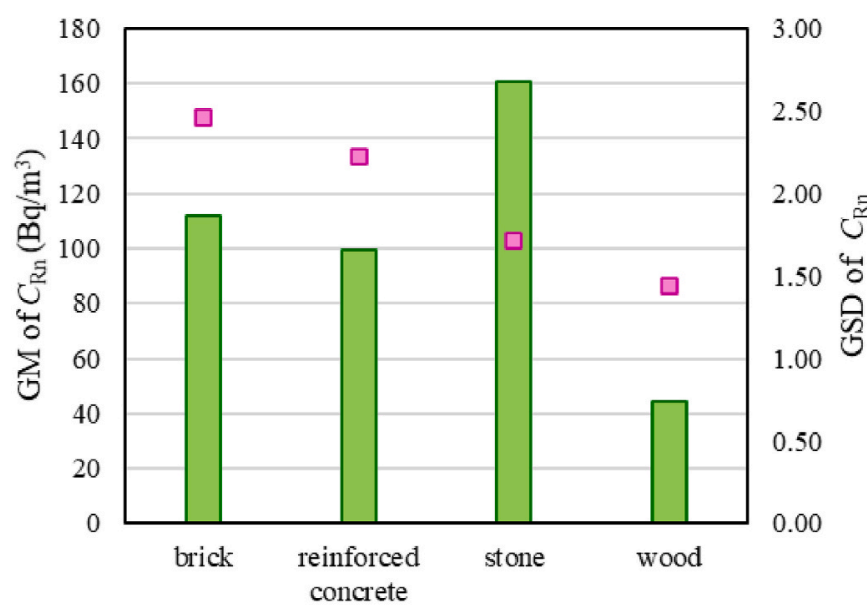

Building materials

Fig. 6. Bar diagram of the $\mathrm{C}_{\mathrm{Rn}}$ geometric mean (GM) and geometric standard deviation (GSD) values in the schools constructed with different building materials.

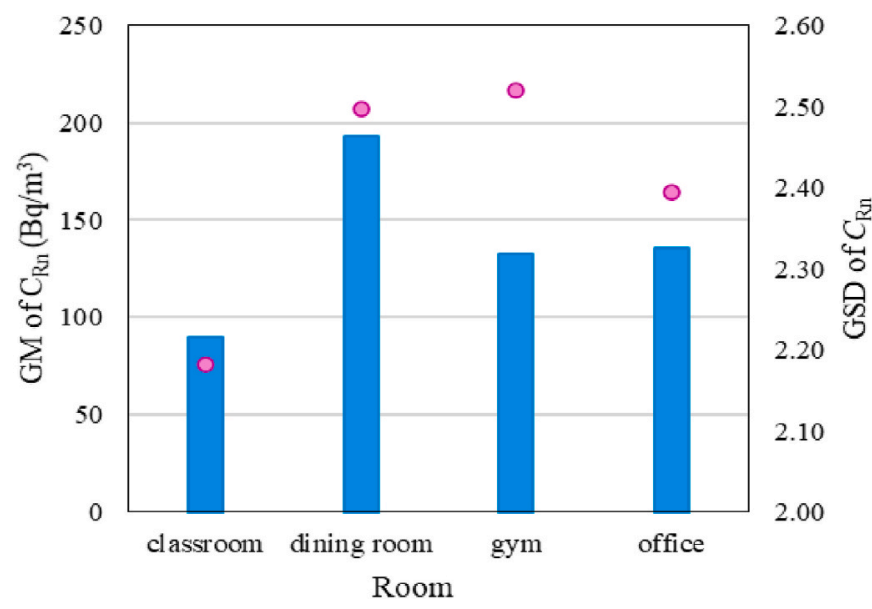

Fig. 7. Bar diagram of the geometric mean (GM) and geometric standard deviation (GSD) values of $\mathrm{C}_{\mathrm{Rn}}$ measured in the different school rooms.

how long the surveyed rooms are used during the day (or week), but the effect of the floor containing the room must also be considered.

The effect of the type of heating in the buildings on the $C_{\mathrm{Rn}}$ variation is shown in Fig. 8. The $C_{\mathrm{Rn}}$ value is higher in buildings with local heating than that in buildings heated by gas and electricity or those connected to a central heating system. The risk of increasing the radon concentration in old buildings with independent heating systems has been investigated in northern Italy [26]. This can be explained by the temperature difference between the outdoor and indoor environments when the local heating system is operated during working hours and deactivated thereafter. The dependence of $C_{\mathrm{Rn}}$ on the type of heating system was also statistically significant $(p<0.0001)$, with a relatively low squared correlation ratio of $\eta=0.02$, (Table 4 ).

Furthermore, the effect of ventilation on $C_{\mathrm{Rn}}$ in the observed buildings was investigated. The correlation was found to be significant at $\eta=$ 0.04 , ( $p<0.0001$ ), (Table 4). Additionally, the association between $C_{\mathrm{Rn}}$ and the implemented energy efficiency measures in the school buildings was tested, which proved to be insignificant, $p>0.05$ in Table 4. Our analysis revealed that the presence of a ventilation system increased $C_{\mathrm{Rn}}$. Ventilation systems exert a positive pressure on buildings or may induce a negative pressure, which increases radon infiltration in buildings [27]. However, due to the implemented energy efficiency measures, the thermal energy in the buildings is conserved, and insulation is installed

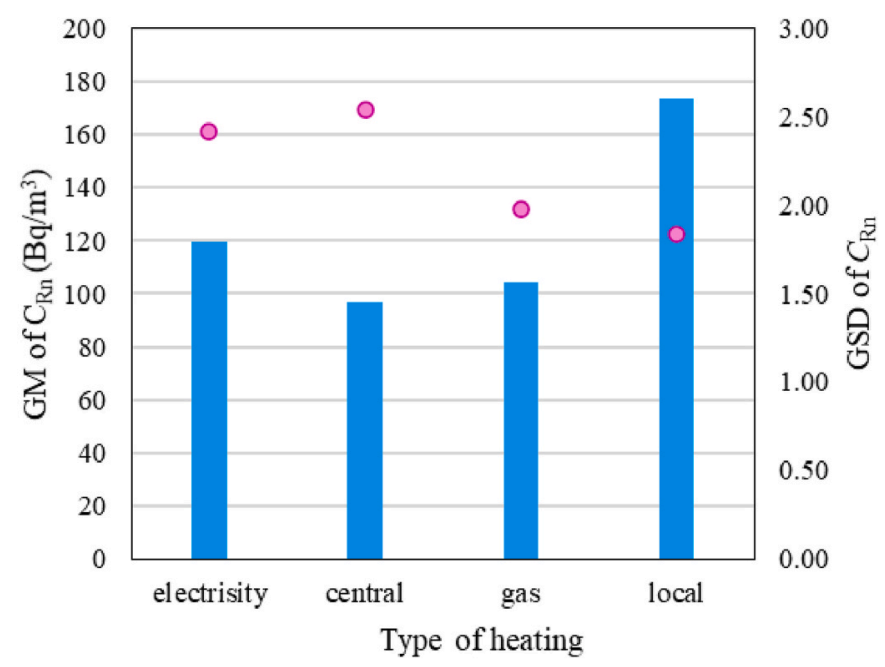

Fig. 8. Bar diagram of the $\mathrm{C}_{\mathrm{Rn}}$ geometric mean (GM) and geometric standard deviation (GSD) values in the schools with different types of heating.

on the walls in addition to PVC windows. Consequently, the indoor environment is hermetically sealed with a reduced outdoor/indoor air circulation, and an increased $C_{\mathrm{Rn}}$ level is expected [11]. Therefore, further analysis showed a crossing effect between building ventilation and energy measures. Hence, they cannot be considered separately. In the surveyed schools, ventilation systems occur only in buildings with implemented energy efficiency measures, which is related to a high $C_{\mathrm{Rn}}$. The ventilation systems in these buildings are designed for energy efficiency to reduce the thermal loss by increasing the building airtightness. This ensures that the thermal loss is minimized while simultaneously maintaining the rate of air exchange at an appropriate level [28]. This effect could explain the reduction in $C_{\mathrm{Rn}}$ in our study. Nevertheless, this result should be carefully investigated in future surveys of buildings with public access.

Furthermore, the $C_{\mathrm{Rn}}$ data were grouped according to the floors in the building, and its influence on the $C_{\mathrm{Rn}}$ variation was analysed. A corresponding significant correlation occurred with a squared correlation ratio of $\eta=0.12, p<0.0001$, (Table 4). The GM and GSD values of $C_{\mathrm{Rn}}$ are shown in Fig. 9. The highest $C_{\mathrm{Rn}}$ values were measured in the basements of the buildings, followed by $C_{\mathrm{Rn}}$ on the ground floors, while low $C_{\mathrm{Rn}}$ values were measured on the first and second floors, which did not differ from each other. This trend, also confirmed in a number of published studies $[6,29]$, indicates that the soil under buildings is the

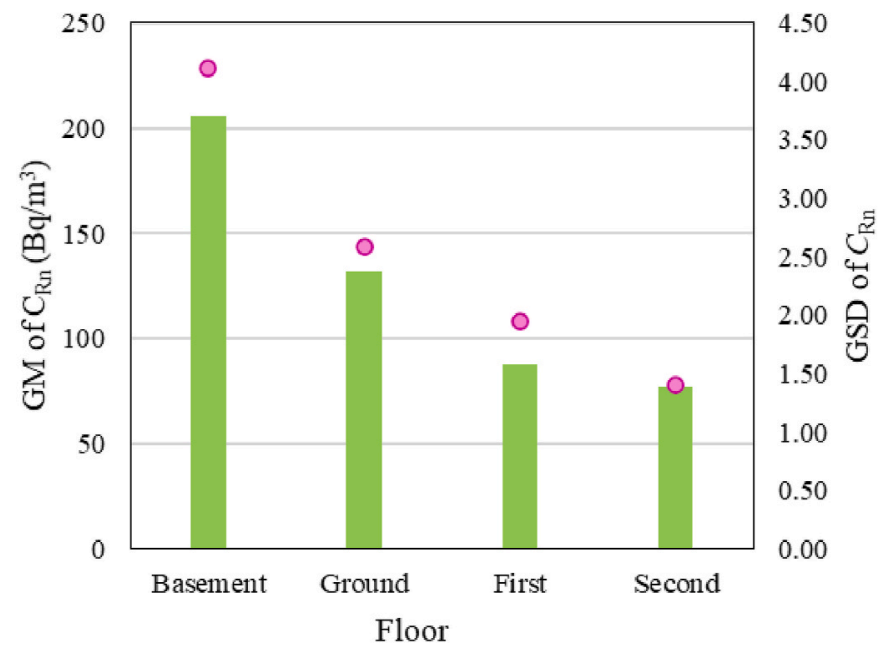

Fig. 9. Bar diagram of the geometric mean (GM) and geometric standard deviation (GSD) values of $\mathrm{C}_{\mathrm{Rn}}$ measured on the different floors. 
dominant source of radon (moving away from the source, the radon concentration decreases).

In addition, the magnitude of the pressure gradient causing the radon inflow into a building is directly related to the floor. Thus, the floor not only affects the insulation effect of the building but also the building radon dynamics. Interestingly, in this case, with increasing floor, in addition to $C_{\mathrm{Rn}}$ decreasing, the GSD also decreases, i.e., the results become more homogeneous. The results of the study and analysis indicate that measurements of $C_{\mathrm{Rn}}$ should be carried out on the basement floor if it is used and throughout the ground floor. Measurements should also occur on the first floor of the building but not in all rooms on the first floor. The presence of a basement in the building influences its $C_{\mathrm{Rn}}$ variation, in the same way the floor does. In our case, the analysis showed that there are no differences between the $C_{\mathrm{Rn}}$ values measured in buildings without and with a basement, i.e., there is no significant relationship between $C_{\mathrm{Rn}}$ and basement occurrence. An assumption of overlaps in the effect of a basement is made, and the $C_{\mathrm{Rn}}$ data grouped by the floors of buildings with and without a basement are further analysed.

The GM and GSD values of $C_{\mathrm{Rn}}$ are shown in Fig. 10. It is clear that in buildings with a basement, $C_{\mathrm{Rn}}$ between the basement and ground floors and between the ground floor and first floor is reduced, while there are no differences between the first and second floors. Differences in $C_{\mathrm{Rn}}$ exist between the ground floor and the first floor, but there are no differences between the first and second floors in buildings without a basement. An interesting fact is that $C_{\mathrm{Rn}}$ on the first and second floors is higher in buildings with a basement than that in buildings without a basement, as shown in Fig. 10. This fact can be explained based on the basement usage in the buildings. Usually, the basement contains dining rooms (canteens) or is used for other purposes. An open basement probably provides an easy way for radon to reach the upper floors, which explains the high radon concentrations on the first and second floors in the buildings with a basement. According to this grouping, the squared correlation ratio of $C_{\mathrm{Rn}}$ with the floor number is $\eta=0.20$ for buildings without a basement and $\eta=0.10$ for buildings with a basement (Table 4).

\section{4. $C_{R n}$ difference within the school buildings}

Previous analyses have shown that the characteristics of a building/ room, such as the year of building construction, building materials, type and position of a room, type of heating, ventilation, and energy efficiency measures, contribute to significant differences in $C_{\mathrm{Rn}}$ between school buildings. The characteristics of the buildings are constant for each school, while the characteristics of the room (position and type) additionally contribute to any differences in $C_{\mathrm{Rn}}$ within the school. Therefore, further analyses evaluated the $C_{\mathrm{Rn}}$ distribution on individual floors and across the rooms on the same floor.

\subsubsection{Floor by floor variations}

In each building, the CV and GSD were determined for two consecutive floors with more than one $C_{\mathrm{Rn}}$ result per floor. The obtained values are listed in Table 5 together with the CV and GSD values of $C_{\mathrm{Rn}}$ per floor. The building of ID 8 was not considered in this table because it only contains one floor.

The ranges of the CV and GSD values, which corresponds to the variations between the basement and ground $(B+G)$ and between the ground and first floors $(G+F)$, in each school were greater than the variations between the first and second $(\mathrm{F}+\mathrm{S})$ floors (KW, $\mathrm{p}<0.05)$. Applying the Kruskal-Wallis test on the CV and GSD values, which exhibited variations within the floors, the test results again were significant (KW, $p<0.05$ ). Further analysis showed that the CV and GSD values corresponding to the ground floor significantly differed from the values corresponding to the first and second floors, while the variations in the values on the first and second floors did not differ from each other. Finally, we compared the variations between $G+F$ to the variations across the ground floor and first floor. Only the variations on the first floor differed from the variations between the ground and first floors (G $+F$ ), while the variations across the ground floor did not differ from those between the ground and first floors $(G+F)$. The analysis confirmed our previous recommendation that measurements should be performed in rooms located on the basement and ground floors, as well as on the first floor. The measurements on these floors could yield results representative of the measured school building. Reducing the number of measurements rooms in the building lead the measurement of more schools.

\subsubsection{Room by room variation}

Table 6 lists the values of CV and GSD that correspond to the $C_{\mathrm{Rn}}$ variations between the classrooms (Cl.) and offices (Of.) on the ground and first floors. The other rooms, gyms and dining rooms, as well as the basement and the second floor, are not included in this analysis due to the insufficient measurements in the respective categories. The analysis indicates that the $C_{\mathrm{Rn}}$ variations ( $\mathrm{CV}$ and GSD) between the classrooms and offices on the ground and first floors are not different. This implies that the variations in the classrooms and offices on a certain floor originate from the same population and exhibit the same distribution.

\subsection{Radon exposure assessment}

The health impact effect on the pupils, teachers and workers in the surveyed schools was expressed as the effective dose $(E)$. The $E$ assessment is performed with the following equation:

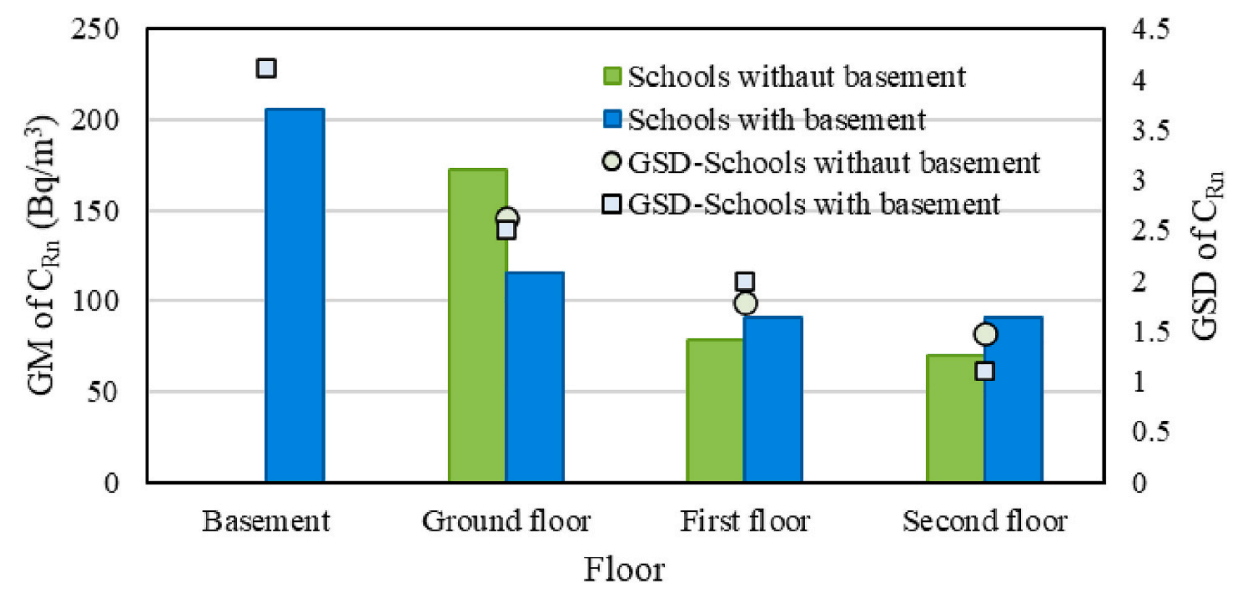

Fig. 10. Bar diagram of the geometric mean (GM) and geometric standard deviation (GSD) values of $\mathrm{C}_{\mathrm{Rn}}$, measured on the different floors of buildings with and without a basement. 
Table 5

Variation in $C_{\mathrm{Rn}}$ between the floors and within the floors.

\begin{tabular}{|c|c|c|c|c|c|c|c|c|c|c|c|c|c|c|}
\hline \multirow[t]{2}{*}{ ID } & \multicolumn{2}{|l|}{$B+G$} & \multicolumn{2}{|l|}{$\mathrm{G}+\mathrm{F}$} & \multicolumn{2}{|l|}{$F+S$} & \multicolumn{2}{|l|}{ B } & \multicolumn{2}{|l|}{ G } & \multicolumn{2}{|l|}{$\mathrm{F}$} & \multicolumn{2}{|l|}{$S$} \\
\hline & $\mathrm{CV}$ & GSD & $\mathrm{CV}$ & GSD & $\mathrm{CV}$ & GSD & $\mathrm{CV}$ & GSD & $\mathrm{CV}$ & GSD & $\mathrm{CV}$ & GSD & $\mathrm{CV}$ & GSD \\
\hline 1 & & & $73 \%$ & 2.12 & & & & & $63 \%$ & 2.18 & $51 \%$ & 1.73 & & \\
\hline 5 & & & $65 \%$ & 1.71 & & & & & $38 \%$ & 1.49 & $37 \%$ & 1.47 & & \\
\hline 6 & & & $63 \%$ & 1.60 & & & & & $65 \%$ & 1.80 & $26 \%$ & 1.35 & & \\
\hline 7 & & & $92 \%$ & 2.05 & & & & & $59 \%$ & 1.98 & $15 \%$ & 1.17 & & \\
\hline 9 & & & $93 \%$ & 1.79 & & & & & $62 \%$ & 1.61 & $25 \%$ & 1.36 & & \\
\hline 12 & & & $79 \%$ & 1.70 & & & & & $84 \%$ & 2.33 & $16 \%$ & 1.19 & & \\
\hline 13 & & & $63 \%$ & 1.79 & & & & & $47 \%$ & 1.64 & $130 \%$ & 2.16 & & \\
\hline 14 & $148 \%$ & 2.53 & $111 \%$ & 2.69 & & & $61 \%$ & 2.04 & $48 \%$ & 1.69 & $26 \%$ & 1.31 & & \\
\hline 15 & & & $101 \%$ & 2.18 & & & & & & & $8 \%$ & 1.12 & & \\
\hline 16 & & & $23 \%$ & 1.25 & $23 \%$ & 1.29 & & & $83 \%$ & 1.87 & $43 \%$ & 1.44 & $9 \%$ & 1.10 \\
\hline 10 & & & $45 \%$ & 1.50 & $21 \%$ & 1.23 & & & $84 \%$ & 2.04 & $41 \%$ & 1.47 & $3 \%$ & 1.04 \\
\hline 11 & & & & & $17 \%$ & 1.20 & & & $91 \%$ & 3.62 & $27 \%$ & 1.34 & $14 \%$ & 1.19 \\
\hline 2 & & & & & & & & & $49 \%$ & 1.64 & & & & \\
\hline 3 & & & $62 \%$ & 1.89 & $27 \%$ & 1.35 & & & $89 \%$ & 2.48 & $71 \%$ & 1.77 & $11 \%$ & 1.12 \\
\hline 4 & $81 \%$ & 2.32 & $46 \%$ & 1.52 & & & $0.2 \%$ & 1.00 & $23 \%$ & 1.28 & $23 \%$ & 1.25 & & \\
\hline Minimum & $81 \%$ & 2.32 & $23 \%$ & 1.25 & $17 \%$ & 1.20 & $0.2 \%$ & 1.00 & $23 \%$ & 1.28 & $8 \%$ & 1.12 & $3 \%$ & 1.04 \\
\hline Maximum & $148 \%$ & 2.53 & $111 \%$ & 2.69 & $27 \%$ & 1.35 & $61 \%$ & 2.04 & $91 \%$ & 3.62 & $130 \%$ & 2.16 & $14 \%$ & 1.19 \\
\hline Median & $115 \%$ & 2.43 & $65 \%$ & 1.79 & $22 \%$ & 1.26 & $31 \%$ & 1.52 & $62 \%$ & 1.84 & $27 \%$ & 1.35 & $10 \%$ & 1.11 \\
\hline Average & $115 \%$ & 2.43 & $70 \%$ & 1.83 & $22 \%$ & 1.27 & $31 \%$ & 1.52 & $63 \%$ & 1.97 & $39 \%$ & 1.44 & $9 \%$ & 1.11 \\
\hline
\end{tabular}

B-basement, G-ground floor, F-first floor, S-second floor.

Table 6

Variation in $C_{\mathrm{Rn}}$ (CV and GSD) between the classrooms (Cl.) and offices (Of.) on the ground $(\mathrm{G})$ and firs $(\mathrm{F})$ floors of the school buildings.

\begin{tabular}{|c|c|c|c|c|c|c|c|c|}
\hline \multirow[t]{2}{*}{ ID } & \multicolumn{2}{|l|}{ Cl. (G) } & \multicolumn{2}{|c|}{ Of. (G) } & \multicolumn{2}{|c|}{ Cl. (F) } & \multicolumn{2}{|c|}{ Of. (F) } \\
\hline & $\mathrm{CV}$ & GSD & $\mathrm{CV}$ & GSD & $\mathrm{CV}$ & GSD & $\mathrm{CV}$ & GSD \\
\hline 1 & $53 \%$ & 2.07 & $67 \%$ & 2.30 & $33 \%$ & 1.48 & $23 \%$ & 1.31 \\
\hline 5 & $58 \%$ & 1.90 & $73 \%$ & 3.77 & $15 \%$ & 1.18 & $14 \%$ & 1.16 \\
\hline 6 & $9 \%$ & 1.12 & $64 \%$ & 1.77 & $21 \%$ & 1.32 & & \\
\hline 7 & $37 \%$ & 1.77 & $67 \%$ & 1.97 & $16 \%$ & 1.19 & & \\
\hline 8 & $39 \%$ & 1.49 & $34 \%$ & 1.44 & & & & \\
\hline 9 & $45 \%$ & 1.55 & $41 \%$ & 1.52 & $6 \%$ & 1.07 & $79 \%$ & 4.55 \\
\hline 12 & $31 \%$ & 1.35 & $70 \%$ & 2.25 & $32 \%$ & 1.31 & $49 \%$ & 1.58 \\
\hline 13 & $109 \%$ & 2.09 & $60 \%$ & 1.74 & $30 \%$ & 1.36 & $36 \%$ & 1.42 \\
\hline 14 & $114 \%$ & 4.74 & $61 \%$ & 2.32 & $31 \%$ & 1.39 & $15 \%$ & 1.24 \\
\hline 15 & $61 \%$ & 2.31 & $78 \%$ & 4.44 & $31 \%$ & 1.43 & & \\
\hline 16 & $17 \%$ & 1.20 & $14 \%$ & 1.22 & $23 \%$ & 1.25 & & \\
\hline 10 & $47 \%$ & 1.84 & & & & & $28 \%$ & 1.38 \\
\hline 11 & & & & & $8 \%$ & 1.12 & & \\
\hline 2 & $20 \%$ & 1.30 & $43 \%$ & 1.98 & & & & \\
\hline 3 & $26 \%$ & 1.41 & $33 \%$ & 1.50 & $37 \%$ & 1.49 & & \\
\hline 4 & $62 \%$ & 1.83 & & & $20 \%$ & 1.27 & $30 \%$ & 1.43 \\
\hline Minimum & $9 \%$ & 1.12 & $14 \%$ & 1.22 & $6 \%$ & 1.07 & $14 \%$ & 1.16 \\
\hline Maximum & $114 \%$ & 4.74 & $78 \%$ & 4.44 & $33 \%$ & 1.48 & $79 \%$ & 4.55 \\
\hline Median & $46 \%$ & 1.80 & $64 \%$ & 1.97 & $23 \%$ & 1.31 & $28 \%$ & 1.38 \\
\hline Average & $52 \%$ & 1.95 & $57 \%$ & 2.25 & $22 \%$ & 1.28 & $35 \%$ & 1.81 \\
\hline
\end{tabular}

$E=C_{\mathrm{Rn}} F \cdot C F$

where $E$ is in mSv; $C_{\mathrm{Rn}}$ is the average indoor radon concentration in Bq/ $\mathrm{m}^{3} ; F$ is the equilibrium factor between radon gas and its decay product, where the standard assumption of $F=0.4$ for most indoor situations is applied [1]; $t$ is exposure time in hours and $C F=6.710^{-6}$ $\mathrm{mSv} /\left[\left(\mathrm{Bq} \cdot \mathrm{h} / \mathrm{m}^{3}\right)\right]$ is radon dose coefficient [30].

The effective dose was estimated, assuming a standard occupancy time of $1200 \mathrm{~h}$ for the pupils, $1600 \mathrm{~h}$ for the teachers due to summer vacation and $2000 \mathrm{~h}$ for the other workers in the schools per year. The results are summarized in Table 7 . The highest doses are received by the pupils and staff members, as expected, in the schools in the Parvomaj and Sopot municipalities.

\section{Conclusions}

To assess the radon concentration spatial distribution in school buildings according to different factors and to optimize the measurement procedure, an analysis of the survey results on 16 school buildings was carried out. There were 428 detectors provided for $C_{\mathrm{Rn}}$ measurements in all the rooms of the surveyed buildings, and 347 detectors were returned to the laboratory, including duplicate detectors, or a detector loss of $18.8 \%$ occurred in the survey. The sampling period in the rooms of the surveyed school buildings lasted from September 2018 to April 2019. Quality control verification in this study was performed with duplicate detectors, which is a good practice to ensure high-quality results. An evaluation of the results of 16 pairs of detectors showed that $86 \%$ yielded acceptable results, which confirms the quality of the study. The arithmetic mean $\left(\mathrm{AM}=160 \mathrm{~Bq} / \mathrm{m}^{3}\right)$ and geometric mean $(108 \mathrm{~Bq} /$ $\mathrm{m}^{3}$ ) of 331 rooms in 16 observed school buildings were determined. The percentage of rooms with a $C_{\mathrm{Rn}}$ value above $100 \mathrm{~Bq} / \mathrm{m}^{3}$ was $11 \%$ (36 rooms). In regard to the high values measured in the school rooms, recommendations have been formulated to reduce the radon concentration. The effective dose due to radon exposure in the municipalities, for the pupils ranged from 0.26 to $1.68 \mathrm{mSv} / \mathrm{y}$, and for the teachers, it ranged from 0.36 to $2.32 \mathrm{mSv} / \mathrm{y}$, while the effective dose for the other workers ranged from 0.4 to $2.58 \mathrm{mSv} / \mathrm{y}$.

The analysis of the results revealed significant differences in $C_{\mathrm{Rn}}$ between and within the school buildings. The effect of specific factors influencing the $C_{\mathrm{Rn}}$ variations was examined, and conclusions were drawn. The differences in $C_{\mathrm{Rn}}$ between the school buildings occurred due to the differences in geographical location and site geology. This was also confirmed by the influence of certain building factors on the

Table 7

Effective dose of radon exposure for the pupils, teachers and workers in the schools by the municipality.

\begin{tabular}{|c|c|c|c|c|c|c|}
\hline & \multicolumn{6}{|l|}{$E(\mathrm{mSv} / \mathrm{y})$} \\
\hline & Plovdiv province & Asenovgrad & Karlovo & Plovdiv & Parvomaj & Sopot \\
\hline Workers & 0.86 & 0.51 & 0.40 & 0.79 & 2.58 & 1.75 \\
\hline Teachers & 0.69 & 0.41 & 0.32 & 0.63 & 2.06 & 1.40 \\
\hline Pupils & 0.51 & 0.31 & 0.24 & 0.48 & 1.55 & 1.05 \\
\hline
\end{tabular}


variances in the measured $C_{\mathrm{Rn}}$. Specifically, in our study, this was confirmed by the fact that high $C_{\mathrm{Rn}}$ values were measured in old buildings in which ageing created cracks and dilated pores enabling radon to easily reach the indoor environment from the soil, mostly accumulating in the basement or ground floor, depending on which space is in direct contact with the soil. The underlying soil as the main source of $\mathrm{C}_{\mathrm{Rn}}$ was confirmed in our study by the small contribution of building materials to the $C_{\mathrm{Rn}}$ variation. In our study, it was also demonstrated that the type of heating as well whether the school building contained a ventilation system and/or energy efficiency measures, albeit to a lesser extent, affected the $C_{\mathrm{Rn}}$ variation between the school buildings. Considering the $C_{\mathrm{Rn}}$ measurements conducted in the different rooms, the type of room also affected the differences in the radon concentration between the schools, but the contribution was small.

To verify the national procedure for radon measurements in public buildings, according to which radon measurements should be performed in each occupied building room, an analysis of the $C_{\mathrm{Rn}}$ variations within the school buildings was performed. For that purpose, the $C_{\mathrm{Rn}}$ variations expressed through the CV and GSD were analysed floor by floor and room by room. Considering the floors: among the ground floor and first and second floors, the analysis showed that the $C_{\mathrm{Rn}}$ variations were significant only between the ground floor and the first floor, while the variations between the first and second floors were insignificant. Further analysis revealed that the $C_{\mathrm{Rn}}$ variations between the ground and first floors exhibited the same value range as the variations in $C_{\mathrm{Rn}}$ measured on the ground floor. Finally, in our study, the analysis of the CV and GSD for the classroom by classroom and office by office variation indicated that they were similar on the ground floor and first floor. The vertical room by room variations in $C_{\mathrm{Rn}}$ were much less pronounced than the horizontal variations, which were much more notable among the school buildings than within the buildings themselves.

Based on the main conclusions, our recommendations for the design of further $C_{\mathrm{Rn}}$ surveys in schools are as follows: (1) For radon surveys in buildings with characteristics similar to those of the surveyed buildings, we recommend including as many school buildings as possible. (2) Most of the measurements should be carried out in the occupied rooms on the basement and ground floors, while a small number of measurements on the first and second floors are sufficient. (3) Additionally, to more realistically assess $C_{\mathrm{Rn}}$ in schools, it is reasonable to consider all types of rooms.

\section{Declaration of competing interest}

The authors declare that they have no known competing financial interests or personal relationships that could have appeared to influence the work reported in this paper.

\section{Acknowledgements}

This work is supported by the Bulgarian National Science Fund of the Ministry of Education and Science (Project КП-06-H23-1/2018 г).

The authors express their gratitude to the Regional Health Inspectorates of Plovdiv for the well-organized distribution of the CR-39 detectors.

\section{References}

[1] Unscear, Sources and effects of ionising radiation, in: Report to the General Assembly with Scientific Annexes. Annex B. Exposures from Natural Radiation Sources, vol. 1, UNSCEAR 2000 Report, New York: United Nations, 2000.

[2] B.D. Spycher, J.E. Lupatsch, M. Zwahlen, M. Röösli, F. Niggli, M.A. Grotzer, Swiss National Cohort Study Group, Background ionizing radiation and the risk of childhood cancer: a census-based nationwide cohort study, Environ. Health Perspect. 123 (6) (2015) 622-628.
[3] J. Vaupotic, M. Krizman, J. Planinić, J. Pezdic, K. Adamic, P. Stegnar, I. Kobal, Systematic indoor radon and gamma measurements in kindergartens and play schools in Slovenia, Health Phys. 66 (5) (1994) 550-556.

[4] L. Gaidolfi, M.R. Malisan, M. Bucci, S. Cappai, M. Bonomi, L. Verdi, F. Bochicchio, Radon measurements in kindergartens and schools of six Italian regions, Radiat. Protect. Dosim. 78 (1) (1998) 73-76.

[5] H. Synnott, P.A. Colgan, O. Hanley, D. Fenton, The effectiveness of radon remediation in Irish schools, Health Phys. 92 (1) (2007) 50-57.

[6] F. Bochicchio, Z.S. Žunić, C. Carpentieri, S. Antignani, G. Venoso, V. Carelli, et al., Radon in indoor air of primary schools: a systematic survey to evaluate factors affecting radon concentration levels and their variability, Indoor Air 24 (3) (2014) 315-326.

[7] J. Madureira, I. Paciência, J. Rufo, A. Moreira, E. de Oliveira Fernandes, A. Pereira, Radon in indoor air of primary schools: determinant factors, their variability and effective dose, Environ. Geochem. Health 38 (2) (2016) 523-533.

[8] Z. Curguz, G. Venoso, Z.S. Zunic, D. Mirjanic, M. Ampollini, C. Carpentieri, Z. Stojanovska, Spatial Variability of Indoor Radon Concentration in Schools: Implications on Radon Measurement Protocols, Radiation Protection Dosimetry, 2020.

[9] K. Ivanova, Z. Stojanovska, M. Tsenova, V. Badulin, B. Kunovska, Pilot survey of indoor radon in the dwellings of Bulgaria, Radiat. Protect. Dosim. 157 (4) (2013) 594-599.

[10] K. Ivanova, Z. Stojanovska, M. Tsenova, V. Badulin, B. Kunovska, Measurement of indoor radon concentration in kindergartens in Sofia, Bulgaria, Radiat. Protect. Dosim. 162 (2014) 163-166.

[11] K. Ivanova, Z. Stojanovska, M. Tsenova, B. Kunovska, Building-specific factors affecting indoor radon concentration variations in different regions in Bulgaria Air, Qual Atmos Health 10 (9) (2017) 1151-1161.

[12] K. Ivanova, Z. Stojanovska, B. Kunovska, N. Chobanova, V. Badulin, A. Benderev, Analysis of the spatial variation of indoor radon concentrations (national survey in Bulgaria), Environ. Sci. Pollut. Control Ser. 26 (7) (2019) 6971-6979.

[13] K. Ivanova, Z. Stojanovska, Modelling of the temporal indoor radon variation in Bulgaria, Radiat. Environ. Biophys. 58 (3) (2019) 337-344.

[14] A. Radulov, Active faults in the Plovdiv Depression and their long-term slip rate J Geol. Balc. 36 (3-4) (2007) 51-56.

[15] International Organization for Standardization, Measurement of radioactivity in the environment - air: radon-222. Part 4: integrated measurement methods for the determination of the average radon activity concentration in the atmospheric environment using passive sampling and delayed analysis, 2012. ISO 11665-4 2012.

[16] Z. Stojanovska, B. Boev, Z.S. Zunic, P. Bossew, S. Jovevska, Results of radon CR-39 detectors exposed in schools due two different long-term periods, Nukleonika 61 (3) (2016) 385-389.

[17] Z. Stojanovska, B. Boev, Z.S. Zunic, K. Ivanova, M. Ristova, M. Tsenova, S. Ajka V. Taleski, P. Bossew, Variation of indoor radon concentration and gamma dose rate in different outdoor and indoor environments, Radiat. Environ. Biophys. 55 (2) (2016) 171-183.

[18] E. Hulber, Overview of PADC nuclear track readers, Recent trends and solutions Radiation Measurement 44 (9-10) (2009) 821-825.

[19] Z. Stojanovska, K. Ivanova, P. Bossew, B. Boev, Z. Zunic, M. Tsenova, Z. Curguz, P. Kolarz, M. Zdravkovska, M. Ristova, Prediction of long-term indoor radon concentration based on short-term measurements, Nucl Technol Radiat 32 (1) (2017) 77-84.

[20] C. Cosma, A. Cucos-Dinu, B. Papp, R. Begy, C. Sainz, Soil and building material as main sources of indoor radon in Băița-Ștei radon prone area (Romania), J. Environ. Radioact. 116 (2013) 174-179.

[21] S. Rizzo, M. Brai, S. Basile, S. Bellia, S. Hauser, Gamma activity and geochemical features of building materials: estimation of gamma dose rate and indoor radon levels in Sicily, Appl. Radiat. Isot. 55 (2) (2001) 259-265.

[22] Y. Shoeib, M. Thabayneh, Assessment of natural radiation exposure and radon exhalation rate in various samples of Egyptian building materials, Journal of Radiation Research and Applied Sciences 7 (2) (2014) 174-181.

[23] J. Somlai, V. Jobbágy, C. Németh, Z. Gorjánácz, N. Kávási, T. Kovács, Radiation dose from coal slag used as building material in the Transdanubian region of Hungary, Radiat. Protect. Dosim. 118 (1) (2006) 82-87.

[24] M. Karpińska, Z. Mnich, J. Kapała, A. Szpak, The evaluation of indoor radon exposure in houses, Pol. J. Environ. Stud. 18 (6) (2009) 1005-1012.

[25] F. Torgal, S. Jalali, A. Fucic, Toxicity of Building Materials, Woodhead Publishing, Cambridge, UK, 2012

[26] G. Gallelli, D. Panatto, P. Lai, P. Orlando, D. Risso, Relevance of main factors affecting radon concentration in multi-storey buildings in Liguria (Northern Italy), J. Environ. Radioact. 39 (2) (1998) 117-128.

[27] B. Mc Carron, X. Meng, S. Colclough, An investigation into indoor radon concentrations in certified passive house homes, Int. J. Environ. Res. Publ. Health 17 (11) (2020) 4149.

[28] M. Collins, S. Dempsey, Residential energy efficiency retrofits: potential unintended consequences, J. Environ. Plann. Manag. 62 (12) (2019) 2010-2025.

[29] H. Chao, W. Tung, J. Burnett, Influence of ventilation on indoor radon level, Build. Environ. 3 (1997) 527-534.

[30] International Commission on Radiological Protection, Occupational intakes of radionuclides: Part 3. ICRP publication 137, Ann. ICRP 46 (3/4) (2017). 